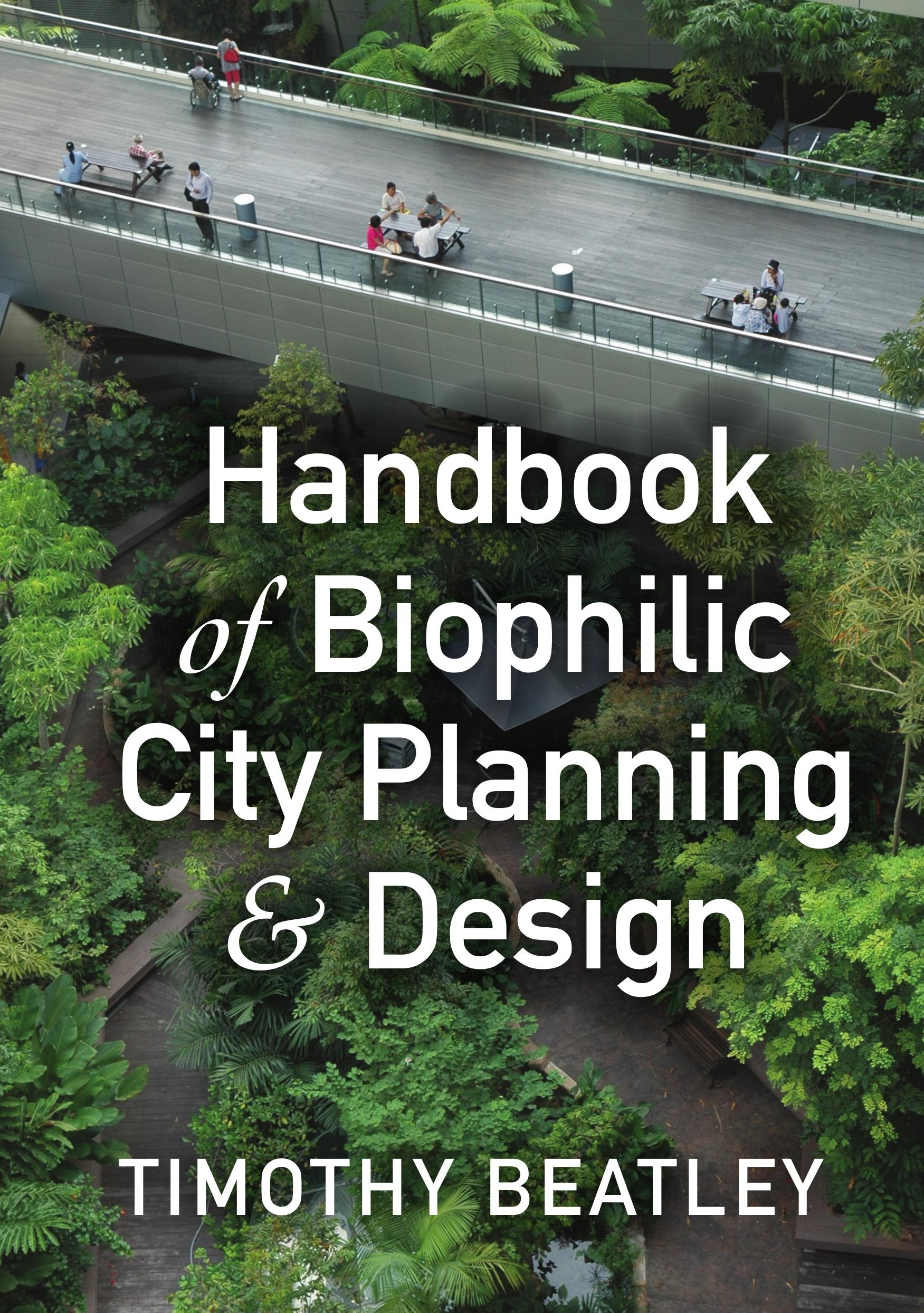



Handbook of Biophilic City Planning and Design 



\section{Handbook of Biophilic City Planning and Design}

Timothy Beatley

\section{Oislandpress}

Washington I Covelo I London 
Copyright @ 2016 Timothy Beatley

All rights reserved under International and Pan-American Copyright Conventions. No part of this book may be reproduced in any form or by any means without permission in writing from the publisher: Island Press, 2000 M Street, NW, Suite 650, Washington, DC 20036

ISLAND PRESS is a trademark of the Center for Resource Economics.

Library of Congress Control Number: 2016938091

Printed on recycled, acid-free paper

Manufactured in the United States of America

$\begin{array}{lllllllllll}10 & 9 & 8 & 7 & 6 & 5 & 4 & 3 & 2 & 1\end{array}$

Keywords: Biodiversity, Biophilia, Biophilic Cities Network, bird-safe buildings, Birmingham (United Kingdom), carbon footprint, climate change, ecosystem, garden, greenbelt, green infrastructure, Green Streets Initiative, health, Intertwine, Khoo Teck Puat Hospital, Milwaukee, nature, nature center, Oslo, park, parklet, Portland, resilience, restoration, San Francisco, Singapore, Stephen Kellert, Sutton Park, urban ecology, vertical garden, VitoriaGastiez (Spain), watershed, Wellington (New Zealand), Zealandia 
To Anneke, Caro, and Jadie 



\section{Contents}

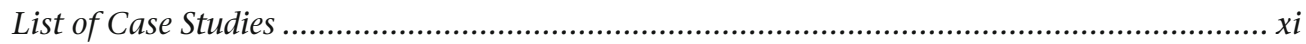

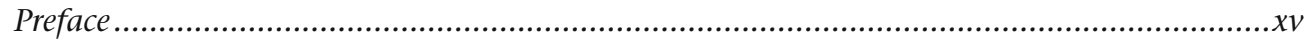

Acknowledgments...................................................................................................

PART 1: THE BACKGROUND AND THEORY OF BIOPHILIC CITIES …........................... 1

Chapter 1: The Power of Urban Nature: The Essential Benefits of Biophilic Urbanism .... 3

Chapter 2. Understanding the Nature of Biophilic Cities............................................ 13

Chapter 3. The Urban Nature Diet: The Many Ways That

Nature Enhances Urban Life........................................................................... 33

Chapter 4. Biophilic Cities and Urban Resilience ....................................................... 41

PART 2: CREATING BIOPHILIC CITIES: EMERGING GLOBAL PRACTICE...................... 49

Chapter 5. Singapore City, Singapore: City in a Garden................................................. 51

Chapter 6. Milwaukee, Wisconsin: From Cream City to Green City ................................ 67

Chapter 7. Wellington, New Zealand: From Town Belt to Blue Belt............................... 75

Chapter 8. Birmingham, United Kingdom: Health, Nature, and Urban Economy ......... 85

Chapter 9. Portland, Oregon: Green Streets in a River City............................................ 93

Chapter 10. San Francisco, California: Biophilic City by the Bay................................. 103

Chapter 11. Oslo, Norway: A City of Fjords and Forests.............................................. 119

Chapter 12. Vitoria-Gasteiz, Spain: Nature in the Compact City .................................. 131 
PART 3: A GLOBAL SURVEY OF INNOVATIVE PRACTICE AND PROJECTS

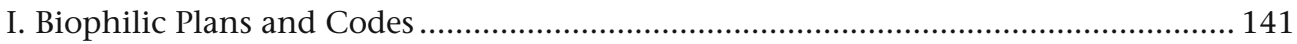

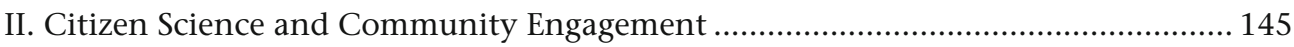

III. Biophilic Architecture and Design .................................................................... 149

IV. Restoring and Reintroducing Nature into the City .............................................. 173

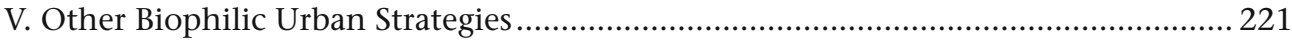

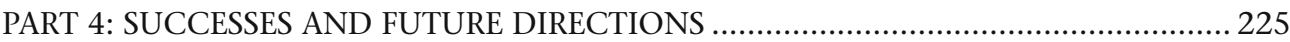

Chapter 13: Lessons from the World's Emerging Biophilic Cities ................................ 227

Chapter 14: Overcoming the Obstacles and Challenges That Remain ..........................2245

Chapter 15: Conclusions: Reimagining Cities of the Future......................................... 255

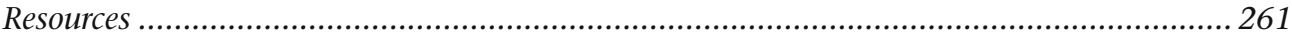

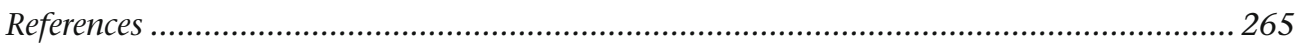

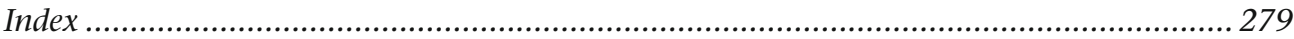




\section{List of Case Studies}

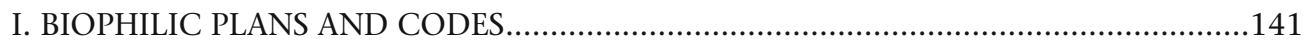

Green Roof Bylaws, Toronto, Ontario, Canada .................................................141

Greenest City Action Plan, Vancouver, British Columbia, Canada ......................142

II. CITIZEN SCIENCE AND COMMUNITY ENGAGEMENT …....................................145

Camping in Urban Parks, New York City, New York ..........................................145

Urban Slender Loris Project, Bangalore, India ..................................................146

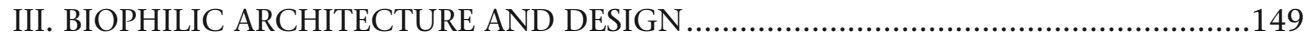

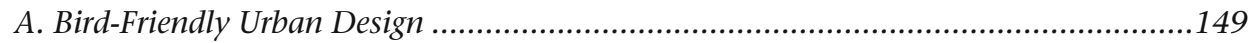

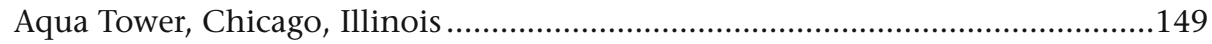

B. Biophilic Factories, Business Parks ..............................................................151

Hero MotoCorp Garden Factory and Global Parts Center, Neemrana, India .......151

Park 20I20, Amsterdam, Netherlands .................................................................152

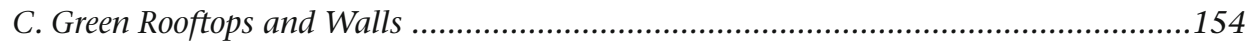

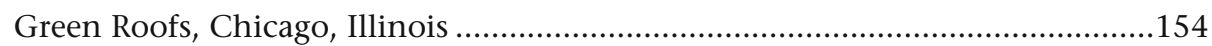

Azoteas Verdes, Mexico City, Mexico ………....................................................155

GreenSkins, Fremantle, Perth, Western Australia ...............................................156

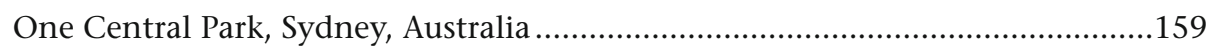

D. Green Terraces and Towers/Vertical Nature.........................................................160

Stacking Green, Ho Chi Minh City, Vietnam .....................................................160

Jardines Verticales, Mexico City, Mexico ............................................................161 


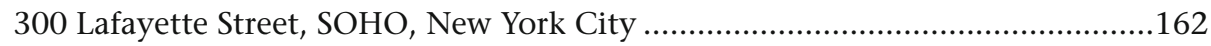

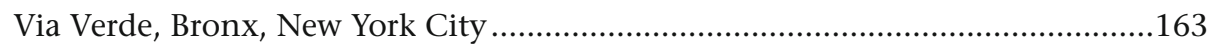

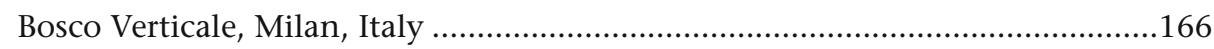

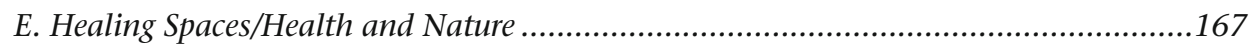

Spaulding Rehabilitation Hospital, Boston, Massachusetts................................167

Credit Valley Hospital, Carlo Fidani Peel Regional Cancer Center, Mississauga, Ontario, Canada .................................................................168

Healey Family Student Center, Georgetown University, Washington, DC..........169

F. Multisensory Biophilic Design ...........................................................................171

Phipps Conservatory and Botanical Gardens, Pittsburgh, Pennsylvania.............171

IV. RESTORING AND REINTRODUCING NATURE INTO THE CITY ............................173

A. Rivers and Riparian Nature; Blue Urbanism .......................................................173

Revitalizing the Los Angeles River, Los Angeles, California .................................173

James River Riverfront Plan, Richmond, Virginia ...........................................175

Cheonggyecheon Stream Restoration Project, Seoul, South Korea ......................177

St. Louis Great Rivers Greenway District's River Ring, St. Louis, Missouri............178

El Parque del Agua Luis Buñuel, Zaragoza, Spain .............................................179

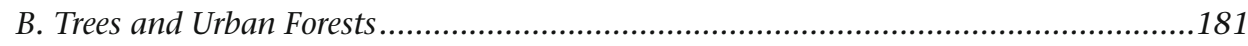

RE:LEAF/Street Tree Initiative/Mayor's Street Tree Program,

London, United Kingdom.....................................................................181

Urban Forest Strategy, Melbourne, Australia .....................................................182

C. Greenways, Greenbelts, Urban Trails................................................................183

Urban Trail Network, Anchorage, Alaska.........................................................183

Chengdu's Ecological Belt and Garden City Vision, Chengdu, China .................184

Trilha TransCarioca (TransCarioca Trail), Rio de Janeiro, Brazil...........................187

D. Green Alleys/Ecological Alleyways .................................................................18

Green Alley Program, Austin, Texas..................................................................188

Green Alleys, Montreal, Quebec, Canada ........................................................191

E. Green Infrastructure and Urban Ecological Strategies ............................................193

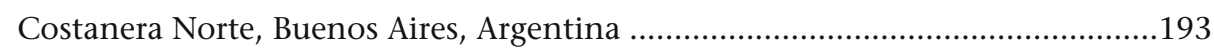

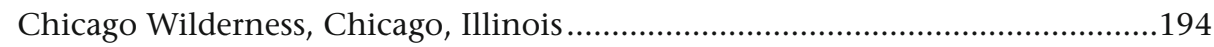

Houston Wilderness, Houston, Texas .................................................................195

Green Grid, London, United Kingdom ..........................................................196

McDowell Sonoran Preserve, Phoenix and Scottsdale, Arizona ...........................197 
F. Innovative Parks and Nature Areas ...................................................................200

Pocket Parks Program, London, United Kingdom.............................................200

Natur-Park Südgelände, Berlin, Germany ....................................................201

Gowanus Canal Sponge Park ${ }^{\mathrm{TM}}$, Brooklyn, New York City, New York .................203

Qiaoyuan Park, Tianjin, China ...................................................................204

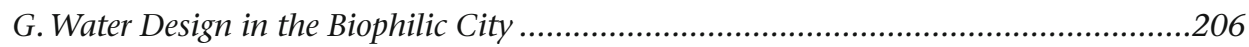

Healthy Harbor Initiative, Baltimore, Maryland ..............................................206

Buffalo Bayou, Houston, Texas ....................................................................207

Green City, Clean Waters Program, Philadelphia, Pennsylvania .........................208

Paley Park, Midtown, New York City, New York .............................................210

H. Wildlife Corridors and Urban Biodiversity Planning.............................................211

Urban Biodiversity, Cape Town, South Africa .................................................211

Wildlife Passages, Edmonton, Alberta, Canada ...................................................212

Urban National Park Planning, Nairobi, Kenya ...............................................213

Milkweeds for Monarchs, St. Louis, Missouri ......................................................214

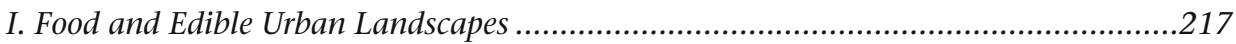

Philadelphia Orchard Project, Philadelphia, Pennsylvania................................217

Beacon Food Forest, Seattle, Washington .......................................................218

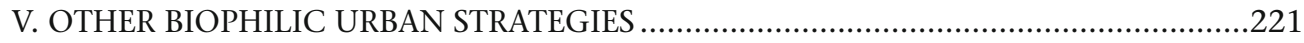

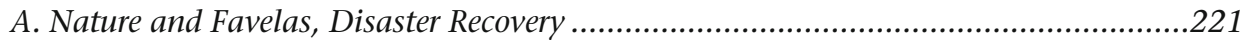

Sitie Ecological Park, Rio de Janeiro, Brazil.....................................................221

Martissant Park, Port-au-Prince, Haiti....................................................................222

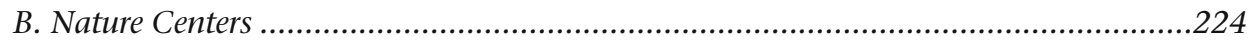

Eden Place Nature Center, Chicago, Illinois..................................................224 



\section{Preface}

This handbook is about the power of nature to create better, more livable, sustainable, and resilient urban neighborhoods and environments.

It is intended to be useful in several ways. First, it provides a comprehensive guide to biophilic urbanism and urban practice, with a wealth of information about how cities can integrate nature into their planning and design processes and projects.

Second, it offers inspiration for how cities of the future might look, feel, and function. As we move into the urban age, we are desperately in need of new models, examples, and frames of reference for the relationship between urban and natural environments. This book also provides more than a modicum of hope in an age where climate change and global environmental degradation cause concern about the future of human and nonhuman life on Earth. While the tools, ideas, strategies, and emerging urban practices reported in these pages do not represent a complete antidote to these global challenges-indeed, what book could? - they are a considerable step in the right direction.

This book synthesizes and expands on the research conducted by the Biophilic Cities Project at the University of Virginia. Begun in 2011, the Project sought to apply the ideas, principles, and practices of the emerging biophilic design movement to the larger scale of cities and metropolitan areas. Focused initially on seven partner cities within the United States and around the world (later expanded to ten cities included in the 2013 Biophilic Cities exhibition and launch event), researchers, practitioners, and politicians collaborated to develop ideas about what a biophilic city is and what it could be in the future.

Much of the work in the initial years of the project focused on fleshing out the concept of biophilic urbanism, and telling the stories of cities leading the way. In October 2013, the Project expanded with the launch of a global Biophilic Cities 
Network, which is intended to help foster a common agenda and a mechanism for sharing insights and collaborating across cultures and geographic boundaries to reimagine a planet of cities that not only value and respect nature but also make it a centerpiece of future design and planning.

Building from the Biophilic Cities Network's efforts, this handbook is intended to advance and solidify some of these nascent ways of understanding and speaking about nature in cities. While we continue to understand and embrace the value of concepts and language-like sustainable cities, resilient cities, regenerative cities-we believe the emphasis on biophilic cities is a useful and necessary addition.

Why? Don't we already speak compellingly of green cities and green infrastructure? Yes, but those descriptors fall short in significant ways. Greening cities is more often understood in terms of the many ways that buildings and neighborhoods can reduce energy consumption and lower ecological footprints. These are important goals, but they don't tell us much about the kinds of neighborhoods, communities, and cities we wish to live in, and they understand nature as only one of many green design and planning arrows in the quiver.

Biophilic, in its emphasis on both the natural world and living things (bio) and the connections with and love of nature (philia), captures more squarely what cities and city planning and design need today. We need something more than nature that serves as infrastructure-we need to speak compellingly and passionately about the need to nurture, protect, care for, and connect with nature. We need to connect with nature for our health and well-being, as scientific evidence increasingly tells us, and biophilic cities captures this importance of urban nature in a way that other contemporary words or language cannot.

What follows are many stories and examples of emerging practice. Part 1 summarizes key ideas, theory, and literature that define biophilic cities and biophilic urbanism. Parts 2 and 3 represent the bulk of the handbook. Part 2 contains full-length chapters on the main cities that the Biophilic Cities Project research has focused on for several years. These cities are also inaugural cities in the new global Biophilic Cities Network. Part 3 features a rich array of shorter examples of urban biophilic innovation from cities around the world. Part 4 presents reflections and lessons about how to advance urban biophilia and biophilic cities. The book closes with a bibliography and an extensive list of resources, including leading books and online resources.

Together the chapters provide a comprehensive understanding of both the theory and the practice of biophilic cities. It is a practical mix of ideas and principles, current urban practice, and future aspirations. The reader will see that much has already been done, or is under way, in cities around the world. 
These are daunting times in terms of the challenges cities face in the decades ahead, but they are also exciting times, when cities are making room for nature, appreciating the importance of nature to health and well-being and to leading meaningful lives. 



\section{Acknowledgments}

There are many people to thank for help in writing this book and in conducting the research that went into these chapters and cases. Many specific individuals have helped collect and supply data and information. Special thanks go to our main contacts and collaborators in the partner cities. While this is by no means a complete list, we owe a special thanks to the following individuals in these cities: Lena Chan (Singapore); Mayor Celia Wade-Brown, Amber Bill, and Charles Dougherty (Wellington); Mike Houck, Matt Burlin, and Linda Dobson (Portland); Matt Howard, Erick Shambarger, and Marcia Caton Campbell (Milwaukee); Per Gunnar Roe and Mark Luccarelli (Oslo); Sabine Courcier and Josee Duplessis (Montreal); Scott Edmondson and Peter Brastow (San Francisco); Nick Grayson and Rob MacKenzie (Birmingham, UK); Cecilia Herzog (Rio de Janeiro); Luis Andres Orive and Rebeca Dios (Vitoria-Gasteiz); and Craig Thomas and David Pijawka (Phoenix), among many others. Other individuals who have been very helpful and have lent support to the biophilic cities idea include Julia Africa, Bill Browning, Herbert Dreisetl, John Hadidian, Stephen Kellert, Stella Tarnay, Helena van Vliet, Catherine Werner, and Jennifer Wolch, among others.

Special thanks must also be given to the Summit Foundation of Washington, DC, and to its director of sustainable cities, Darryl Young, who provides extensive financial (and moral) support for the work, and for the emerging global network of cities. Financial support for this research was provided initially under the grant "Biophilic Urbanism: Global Methods and Metrics," and was followed by additional support to develop the project's web page and newly launched Biophilic Cities Network.

Significant financial support for the Biophilic Cities Project and the event launching the global Biophilic Cities Network was also provided by the George Mitchell Foundation. George Mitchell sadly passed away in 2013, but he will be remembered as a leader and catalyst for sustainable, biophilic design, as evidenced in his work 
with Ian McHarg in designing and building the Woodlands, a green new town ahead of its time. It was a pleasure to get to know George Mitchell, and an honor to have his personal and financial support for the work we have been doing in green urbanism and biophilic cities.

Special thanks are also due Professor Peter Newman, of Curtin University, who has been a partner and close colleague in developing the ideas of biophilic cities and biophilic urbanism. Many of the cities we have examined here, and the projects and people profiled, are due to Peter's suggestions and generous sharing of his immense network of global contacts.

A number of graduate students in the Department of Urban and Environmental Planning, at the University of Virgina, have helped with this project along the way, either working directly on the information and cases presented here, or on some other aspect of the Biophilic Cities Project over the years. These current and former students include Holly Hendrix, Harriett Jameson, Sarah Schramm, Amanda Beck, Mariah Gleason, Briana Bergstrom, Dita Beard, and JD Brown, among others. Special thanks are owed to Carla Jones and Julia Triman who read and edited all parts of this book.

Several of the chapters to follow draw from earlier writing. Some material has appeared earlier in our Biophilic Cities blogs. Several chapters in part 2 draw from earlier published work. An earlier version of the Singapore chapter was published in SiteLines (Foundation for Landscape Studies), and a version of the Oslo chapter was published earlier in the book Green Oslo: Visions, Planning and Discourse (Ashgate), though both have been substantially modified. Two of Beatley's EverGreen columns written for Planning Magazine (longer drafts) make up portions of the chapters on Birmingham and San Francisco. 